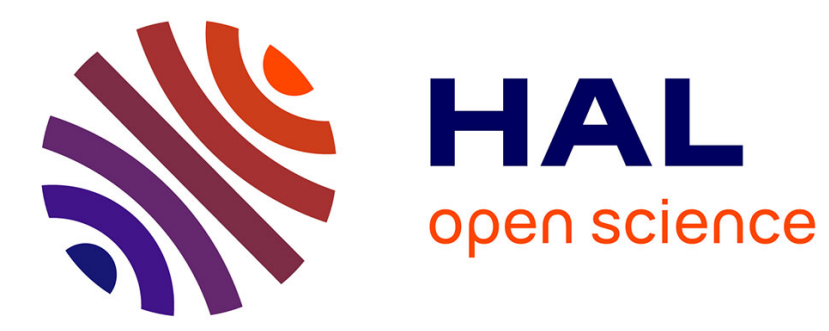

\title{
Exhaustion mechanisms in the Preyield domain of niobium single crystals at low temperatures
}

\author{
A. Boudet, L.P. Kubin
}

\section{To cite this version:}

A. Boudet, L.P. Kubin. Exhaustion mechanisms in the Preyield domain of niobium single crystals at low temperatures. Journal de Physique, 1975, 36 (9), pp.823-833. 10.1051/jphys:01975003609082300 . jpa-00208321

\section{HAL Id: jpa-00208321 https://hal.science/jpa-00208321}

Submitted on 1 Jan 1975

HAL is a multi-disciplinary open access archive for the deposit and dissemination of scientific research documents, whether they are published or not. The documents may come from teaching and research institutions in France or abroad, or from public or private research centers.
L'archive ouverte pluridisciplinaire HAL, est destinée au dépôt et à la diffusion de documents scientifiques de niveau recherche, publiés ou non, émanant des établissements d'enseignement et de recherche français ou étrangers, des laboratoires publics ou privés. 
Classification

Physics Abstracts

7.222

\title{
EXHAUSTION MECHANISMS IN THE PREYIELD DOMAIN OF NIOBIUM SINGLE CRYSTALS AT LOW TEMPERATURES
}

\author{
A. BOUDET and L. P. KUBIN \\ Laboratoire d'Optique Electronique du C.N.R.S. \\ B.P. 4007, 31055 Toulouse Cedex, France \\ (Reçu le 21 février 1975, accepté le 24 avril 1975)
}

\begin{abstract}
Résumé. - Des monocristaux de niobium de haute pureté ont été déformés en tension et par relaxation des contraintes dans le domaine préplastique à des températures comprises entre 4,2 et $70 \mathrm{~K}$.

La pente de la courbe de déformation et la chute de charge pendant une relaxation des contraintes ont été étudiées en fonction de la nature et de la densité des dislocations initialement présentes dans l'échantillon. Il a été montré que dans le domaine préplastique le mouvement des dislocations est gouverné par une interaction thermiquement activée associée à un mécanisme exhaustif.

Ces résultats sont quantitativement décrits par l'interaction avec les impuretés interstitielles de dislocations de type coin dont la longueur subit une fragmentation au cours de leur mouvement.
\end{abstract}

\footnotetext{
Abstract. - Pure niobium single crystals were tested by tension and by stress-relaxation at stresses below the macroscopic yield stress and at temperatures between 4.2 and $70 \mathrm{~K}$.

The slope of the stress-strain curve and the amount of stress relaxation were investigated as a function of the nature and density of dislocations initially present in the sample. In the preyield domain the dislocation mobility was found to be governed by a thermally activated phenomenon associated to an exhaustion mechanism.

This behaviour was quantitatively discussed in a model, in which edge dislocations undergo fragmentation, when the stress increases, as a result of their interaction with interstitial impurities.
}

1. Introduction. - 1.1 THE PREYIELD DOMAIN. The preyield domain can be defined as the domain of stresses in which plastic deformation occurs without any massive increase of the mobile dislocation densities; it is bounded by the anelastic stress and the macroyield stress as defined below. This domain is particularly interesting in BCC metals and at low temperatures because of its large extent in strain (up to 1 or $2 \%$ ) and stress (up to $10^{-2} \mu-\mu$ : shear modulus). Few experimental data for pure materials are available. A peculiar kind of behaviour (exhaustion phenomena) due to the small densities of mobile dislocations is reported in [1] but is not explained in terms of dislocation mechanisms.

The aim of the experiments described below was to investigate the influence of temperature and dislocation densities on the preyield behaviour of pure BCC niobium. Stress relaxations and tensile cycling experiments (between zero stress and a maximum stress) were performed on single crystals at low temperatures.

An attempt was made to give to the experimental data a quantitative form through a general description of the preyield behaviour in the case of zero multiplication of dislocations.
1.2 THE PREYIELD BEHAVIOUR OF BCC METALS. Two methods have been widely used for the study of small deformations : one is the stress relaxation technique [2], the other consists in stress cycling [3].In the latter the microelastic, anelastic and macroelastic critical stresses are defined. In the preyield domain the cycles are not closed, i.e some residual deformation is obtained (cf. Fig. 1). According to the theories of the yield stress of BCC metals [4] and to electron microscopy observations of crystals strained at low temperatures $[5,6,7]$, screw dislocations are not mobile at stresses smaller than the macroyield stress. At a lower stress, the bending of dislocations is stopped when the screw direction is reached, and Frank-Read sources cannot operate. According to this description, only edge dislocations can be mobile in the preyield domain.

Surface-induced slip is known to occur in molybdenum [8]. It is not considered here : only the strain resulting from edge movement is taken into account, for surface slip has not been detected in the $\mathrm{Vb}$ group BCC metals and may not happen in this case.

At low temperatures and at stresses higher than the macroyield stress, the screw dislocation mobility is 


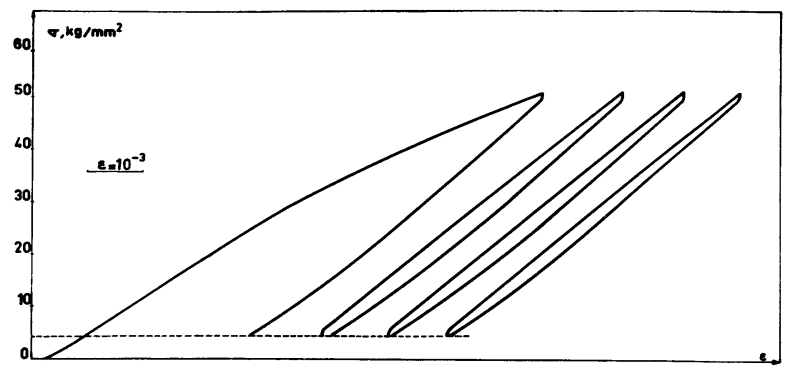

Fig. 1. - Stress cycling at $T=4.2 \mathrm{~K}$ after a $4 \%$ prestrain at room temperature (sample 3).

much lower than the edge dislocation mobility, but, at room temperature with niobium, this is no longer true : screw dislocations of opposite sign can annihilate by cross-slip, so that straining mainly leaves a Frank net of edge and mixed dislocations in the crystal.

This behaviour has been used to introduce in our samples either screw dislocations (by prestrains at $77 \mathrm{~K}$ ) or edge and mixed dislocations (by prestrains at room temperature). Since no dislocation multiplication is possible at low temperatures, the mobile dislocations are those introduced by the prestrain, and their nature and density may thus be controlled.

The preyield domain has been investigated in the temperature range $4.2-70 \mathrm{~K}$, where it has its greater extent and where screw dislocations are sessile.

Previous experiments in that temperature range mainly in iron but also in niobium lead to the following results $[1],[9,10,11,12]$ :

i) Stress relaxation is a logarithmic function of time, in agreement with the laws of thermal activation [9].

ii) Preyield strain is decreased or suppressed by small amounts of impurities.

iii) Exhaustion mechanisms appear during stresscycling (between zero and a maximum stress). The recorded preyield deformation decreases very rapidly as stress cycling proceeds (Fig. 1) and there is generally no residual strain after the third cycle. This is interpreted as exhaustion of the preexisting density of mobile dislocations.

2. Experimental results. - 2.1 EXPERIMENTAL PROCEDURES. - Figure 2 gives the orientations of the tensile axis of the niobium single crystals. The single crystals were prepared by zone melting, and after machining, were purified by annealing for 10 hours at $2050^{\circ} \mathrm{C}$ under a pressure of $10^{-8}$ torr. The total interstitial content $(\mathrm{C}, \mathrm{H}, \mathrm{O}, \mathrm{N})$ was estimated to be about $100 \mathrm{ppm}$.

The low temperature tensile and cooling apparatus has been described already [13]. Small strains $(0.1 \mu$ or $\left.5 \times 10^{-6}\right)$ in the helium temperature range were measured by a LVDT transducer. The strain rate was $0.83 \times 10^{-4} \mathrm{~s}^{-1}$.

The stress relaxation technique was used in order to investigate the influence of prestrain on the amount

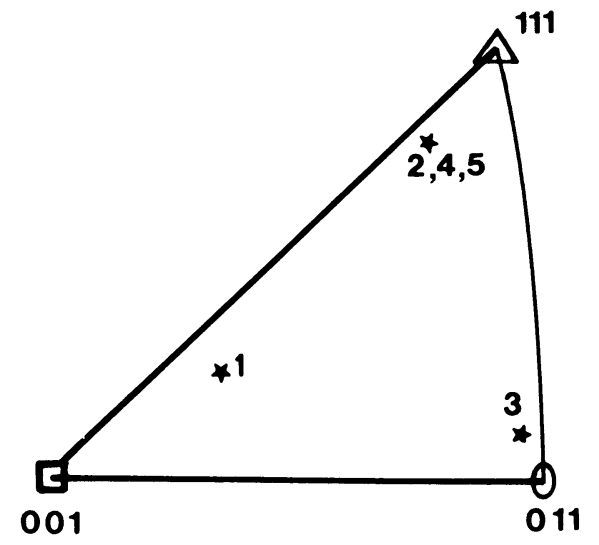

FIG. 2. - Orientations of the tensile axis of the niobium single crystals.

of relaxation. The time interval $t$, during which the stress relaxes by a given amount, is measured as a function of the prestrain $\gamma_{\mathbf{p}}$. If successive stress relaxations starting from the same initial stress are performed, exhaustion mechanisms appear [14]. A pause (delay time) can be observed; it has been shown to be some kind of machine effect.

Stress cycling also allows the exhaustion phenomena to be measured. When, after several cycles, the supply of mobile dislocations is exhausted, the cycles are closed (Fig. 1), i.e the anelastic stress has become the maximum stress of the cycle, and the recorded strain is recoverable. If this reversible strain is deducted from that recorded during the first cycle, what remains is the preyield plastic strain.

The lower stress of the cycles was maintained to $3 \mathrm{~kg} / \mathrm{mm}^{2}$ (instead of 0 ), in order to keep the sample in good alignment. It was assumed that the plastic strain between 0 and $3 \mathrm{~kg} / \mathrm{mm}^{2}$ is negligible when compared to the strains recorded at higher stresses.

2.2 Results. - 2.2.1 Preyield strain during stress cycling. - In figure 1, the maximum stress in the cycle is about $0.6 \sigma_{\mathrm{M}}$ where $\sigma_{\mathrm{M}}$ is the macroyield stress. The recorded strains are $3 \times 10^{-3}$ after the first cycle, $10^{-4}$ after the second one and less than $10^{-6}$ after the third one. This means most of the mobile dislocations are blocked at the end of the first and can be freed again only at higher stresses. The strain during the first cycle, corrected for reversible strains measured on the third cycle, is alone considered here.

2.2.2 Influence of the prestrain. - On figure 3 is reported the plastic preyield strain at $4.2 \mathrm{~K}$, measured on the first cycle, versus the prestrain $\gamma_{\mathrm{p}}$ performed at $300 \mathrm{~K}$. The preplastic strain increases rapidly with the prestrain up to $\gamma_{\mathrm{p}} \simeq 2 \%$ and more slowly thereafter. There are two possible explanations :

i) The prestrains above $2 \%$ do not create a great additional number of dislocations ;

ii) The mobile dislocations created by large prestrains are not mobile in the range of stress of the cycle. 


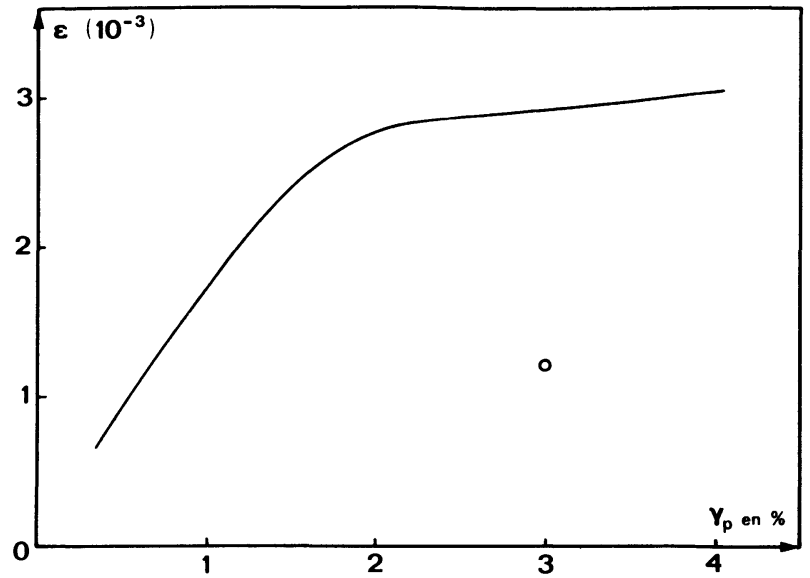

Fig. 3. - Tensile strain of specimen 3 at a stress $\sigma=50 \mathrm{~kg} / \mathrm{mm}^{2}$ (not resolved) and $T=4.2 \mathrm{~K}$ as a function of the prestrain at $293 \mathrm{~K}$. The circle reports the result for a $77 \mathrm{~K}$ prestrain.

In figure 3 it can be seen that a $3 \%$ prestrain at $77 \mathrm{~K}$ is not as efficient as a $1 \%$ prestrain at $293 \mathrm{~K}$. This can be related to the fact that low temperature $(T<220 \mathrm{~K})$ prestrains produce mainly screw dislocations which are sessile in the preyield stage.

The stress-strain curves corresponding to several values of the prestrain (at $300 \mathrm{~K}$ ) are shown in figure 4. The increase in strain and the decrease in hardening at large prestrains are clearly a result of the increase in the edge dislocation density.

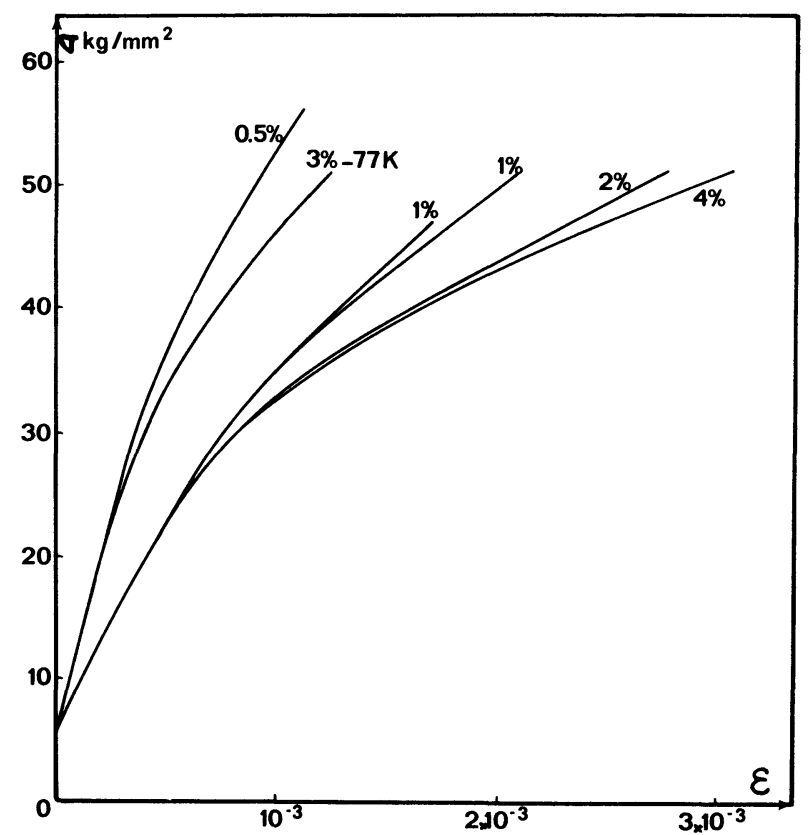

Fig. 4. - Stress-strain curves at $T=4.2 \mathrm{~K}$, for different prestrains at 293 and $77 \mathrm{~K}$. Axial stresses. Sample 3.

Furthermore two substages appear at stresses about $30 \mathrm{~kg} / \mathrm{mm}^{2}$, especially for high values of $\gamma_{\mathrm{p}}$. The reproductibility of the experiments can be checked by comparing two samples prestrained by the same amount $1 \%$.
2.2.3 Influence of the temperature. - Figure 5 shows the successive stress-strain curves of samples 4 and 5 at different temperatures and two amounts of prestrain. The general trends of the curves are the same as at $4.2 \mathrm{~K}$, but for a given value of the stress, the strain appears to increase strongly with temperature. Assuming the same mechanisms, this implies that the deformation is thermally activated.

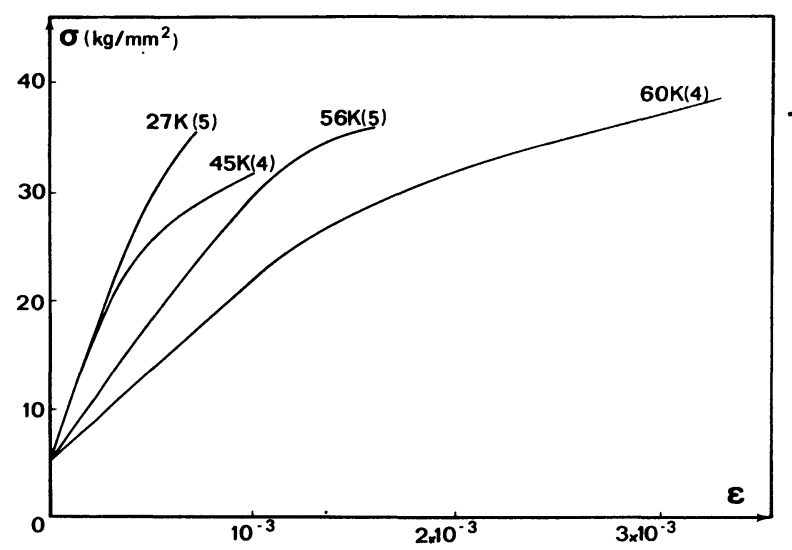

Fig. 5. - Stress-strain curves at different temperatures. Axial stresses. Specimen $4: \gamma_{p}=3 \%$. Specimen $5: \gamma_{p}=2 \%$.

This is more evident from the experiments reported in figure $6:$ after $3 \%$ prestrain, exhaustion cycling is performed at $60 \mathrm{~K}$ and the anelastic stress $\sigma_{\mathrm{A}}$ is equal to the maximum stress of the cycle, $\sigma_{1}$. When the sample is reloaded at $50 \mathrm{~K}$, a change in the hardening slope is recorded at $\sigma_{2}>\sigma_{1}$.

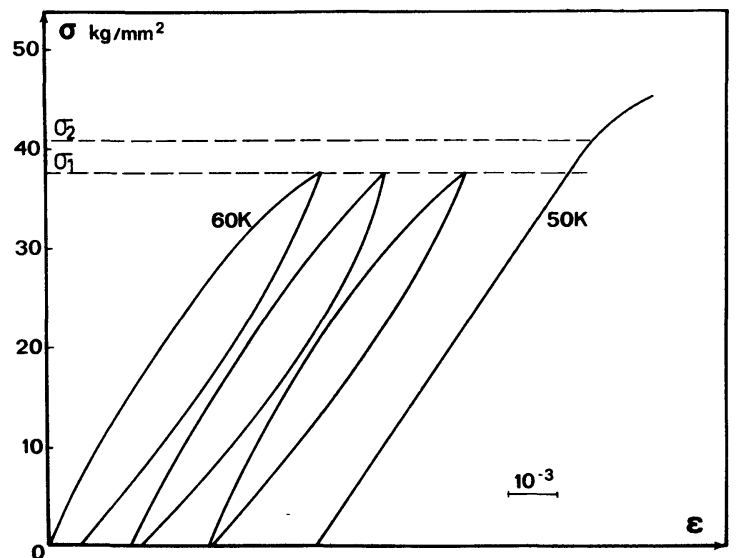

Fig. 6. - After an exhaustion of mobile edge dislocations at $60 \mathrm{~K}$, the anelastic limit increases at lower temperature $(50 \mathrm{~K})$. Axial stresses; specimen $4 ; \gamma_{p}=3 \%$.

For figure 7, the exhaustion cycling was performed at $45 \mathrm{~K}$ and $\sigma_{\mathrm{A}}=\sigma_{1}=32 \mathrm{~kg} / \mathrm{mm}^{2}$. The sample was reloaded at $35 \mathrm{~K}$ and cycles were performed with maximum stresses starting from the value $\sigma_{1}$. The cycles remain closed till $\sigma_{2}=36 \mathrm{~kg} / \mathrm{mm}^{2}$.

These experiments show that $\sigma_{1}$ and $\sigma_{2}$ are the critical stresses at different temperatures for the same 


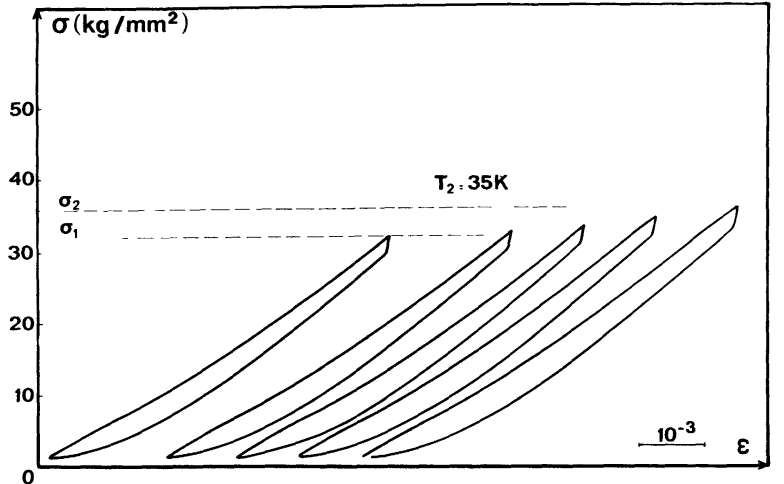

Fig. 7. - After an exhaustion cycling at $45 \mathrm{~K}$, the maximum stress is progressively increased at $35 \mathrm{~K}$ and the cycle opens at a stress $\sigma_{2}$. Axial stresses. $\gamma_{p}=3 \%$. Specimen 4. The particular shape of the loop is due to reversible deformation of the apparatus which can be measured.

grouping of edge dislocations. The liberation of these dislocations from their obstacles is, then, clearly, a thermally activated phenomenon.

2.2.4 Exhaustive stress relaxations. - Experiments have been reported already [14, 15] (specimens 1 and 2). Figure 8 provides the basis for describing the

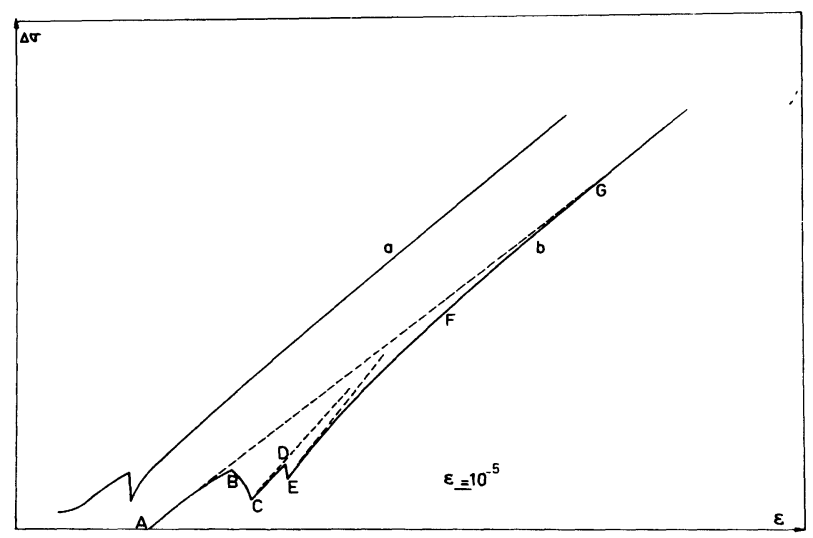

FIG. 8. - Exhaustion stress relaxations (BC, DE) at $4.2 \mathrm{~K}$. a) The full scale is 28.7 to $31.8 \mathrm{~kg} / \mathrm{mm}^{2}$. b) Full scale 38.2 to $41.3 \mathrm{~kg} / \mathrm{mm}^{2}$. Axial stresses.

peculiar nature of exhaustive relaxation : after one relaxation (curve a) or two (BC and $\mathrm{DE}$, curve b) a strain is imposed on the sample; the hardening slope is higher after the stress relaxation; this increase can be interpreted as a lack of mobile dislocations which have been exhausted (liberated by thermal help, then blocked) during the relaxation test. Thus dislocations can be unpinned in two ways :

1) by an increase of the applied stress,

2) by thermal activation, the stress being constant or even decreasing, provided that sufficient time is allowed. Those dislocations are used there, which would have been unpinned at a higher stress in the non-interrupted constant strain rate test.
2.3 Conclusions. - Some general statements can be drawn from these results :

2.3.1 Edge dislocations, created by the room temperature prestrain, are responsible for most of the preyield strain.

2.3.2 At each value of the applied stress, there is a little grouping of mobile dislocations, which can travel a certain distance before being blocked again. Further deformation can be obtained either by increasing the applied stress or by relaxing it. The mobility of this grouping of dislocations is then characterized by a critical stress, the value of which is distributed on the whole preyield range or at least in a large range of stresses.

2.3.3 The movement of each grouping of dislocations is governed by thermal activation.

2.3.4 This distribution of the critical stress values refer to a distribution of different thermally activated events. If all those events were identical, only one critical stress would exist and all the edge dislocations would be liberated at the same stress, definitely exhausting the supply of mobile dislocations. This is obviously not the case. The mechanism responsible from that distribution is supposed to be the interaction between edge dislocations and impurities. The parameter which influences the critical stress, is thought to be the length $l$ of the mobile edge fragments.

3. Quantitative description of the preyield behaviour. - 3.1 BASIC HYPOTHESIS. - Any description of the low temperature preyield properties, in those BCC metals which behave like niobium, has to take account of the influence of temperature, dislocation densities, purity. Little is known about the actual mechanisms of preplasticity, but some aspects, such as interaction or statistical laws can be derived from macroplastic experiments.

At low stresses, according to the models of the macroyield stress [4], screw dislocations are thought to be sessile because of their tridimensional core structure. As a result, Frank-Read source do not operate, and only edge dislocation fragments are mobile. Their total length, $\mathcal{L}$, remains constant (or decreases).

In molybdenum, it has been shown that surface sources operate when the screw component can leave the crystal through the outer surface [8], i.e when the edge component can travel through the crystal. Since this mechanism does not seem to apply to the $\mathrm{Vb}$ group metals $(\mathrm{Nb}, \mathrm{Ta}, \mathrm{V})$ we do not take into account, here, surface effects [16].

Owing to the stress levels involved and to the values of the activation volumes, edge dislocation interactions with interstitial impurities can be supposed to be the major process governing the preyield deformation. This view is supported by many tension or internal friction experiments $[10,11,12]$, [17].

The interaction is, clearly, a core problem. But 
elastic calculations are given by Orowan's or Fleischer's models [18, 19]. In every case, the maximum strength, $F_{\max }$, (at $0 \mathrm{~K}$ ) for depinning the dislocation from the interstitial impurity is :

$$
\tau_{0}=\frac{F_{\max }}{b}=\alpha \frac{\mu b}{l},
$$

where $l$ is the length of the dislocation fragment, and $\alpha$ is a constant $(\alpha \leqslant 1)$.

An exhaustion mechanism has been suggested [9] : edge dislocations are continuously liberated and blocked when the stress increases. This means that there exists a spectrum in the activation energies, or, as shown by our experiments, that each part of the stressstrain curve behaves like a local yield stress, for given (but small) dislocation density and given obstacle strength. If the stress changes, the obstacle strenght and the dislocation density change.

The evolution of the statistical spectrum of $l$ values along the stress-strain curve, will lead to a spreading of the values of $\tau_{0}$ as given by eq. (1). It is assumed here that, at the stress level $\tau_{0}$, only the dislocation fragments of length $l$ can overcome the impurity obstacles. Thermal activation is not considered.

The statistical distribution $N(l)$ can be calculated if the initial distribution, $n(l)$, which in our case results from the prestrain, is known, [ $N$ and $n$ are the number of fragments of lengths between $l$ and $l+\mathrm{d} l]$. Following Kocks [20] and $\mathrm{Li}$ [21] this distribution is of the form :

$$
n(l)=A l \mathrm{e}^{-B l},
$$

where $l$ can be, in a plastically strained sample, the radius of an expanding loop, or the free length of a dislocation line in the forest. Some details and justifications about this distribution law are given in appendix I.

At the absolute zero an increment $\mathrm{d} \tau_{0}$ of the stress gives a strain :

$$
\mathrm{d} \gamma=b \rho \mathrm{d} L
$$

$L$ being the distance travelled by the dislocation.

Another formula is given in [22] :

$$
\mathrm{d} \gamma=b L \mathrm{~d} \rho,
$$

where $\mathrm{d} \rho$ is a change in dislocation density, while $L$ is the distance between thermally activated obstacles.

Here :

$$
\mathrm{d} \rho=l N(l) \mathrm{d} l \text { and } \mathrm{d} \gamma=b L l N(l) \mathrm{d} l
$$

At a finite temperature thermal activation must be taken into account. If, for instance, the activation volume is known as a function of the stress, the stressstrain curve at any temperature can be derived from that at absolute zero. In eq. (1) the stress $\tau_{0}$ should be replaced by the stress $\tau_{T}$.
Because the mechanisms are not clearly understood, a simplified model, aiming mainly at describing the experimental variations and orders of magnitude, is used here.

\section{2 Prestrained dislocation substructures. -} The prestrained substructures are described by eq. (2), which can be written as

$$
n(l) \mathrm{d} l=4 l_{\mathrm{m}}^{-5} l \exp \left(-2 l / l_{\mathrm{m}}\right) \mathrm{d} l
$$

$$
\text { (cf. appendix I) }
$$

where $n(l) \mathrm{d} l$ is the density of fragments of lengths between $l$ and $l+\mathrm{d} l$, by unit volume; $l_{\mathrm{m}}$ is the average length. The prestrain can be taken into account through the values of $l_{\mathrm{m}}$ (or $\mathcal{L}=l_{\mathrm{m}}^{-2}$ ). Figure 9 shows the variation of $n(l)$ with $l$.

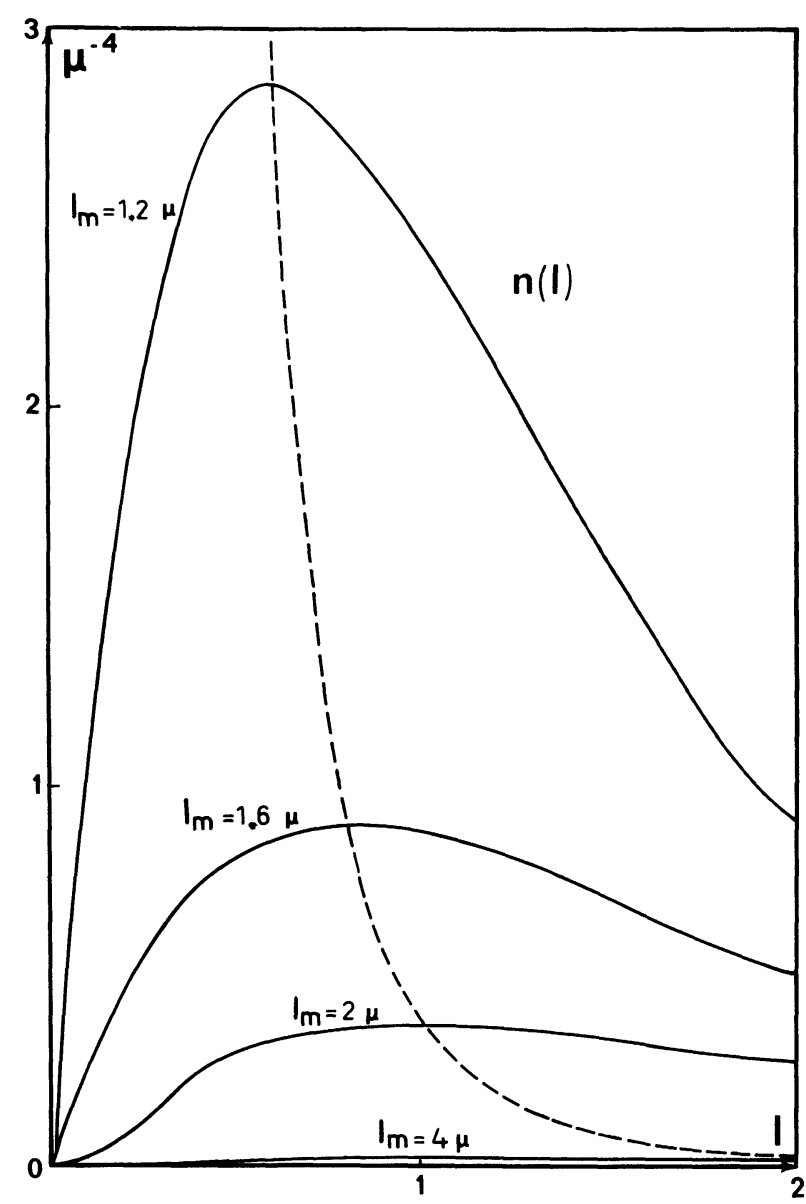

FIG. 9. - Initial number of dislocation fragments per unit volume as a function of their length $l$.

If now $l$ is replaced by $\frac{\alpha \mu b}{\tau_{0}}$ in eq. (4), the distribution of edge dislocations is obtained as a function of their critical stress at the absolute zero :

with

$$
n(l) \mathrm{d} l=-n^{\prime}\left(\tau_{0}\right) \mathrm{d} \tau_{0}
$$

$$
n^{\prime}\left(\tau_{0}\right) \mathrm{d} \tau_{0}=\left(\frac{\tau_{\mathrm{m}}}{2 \alpha \mu b}\right)^{3}\left(\frac{\tau_{\mathrm{m}}}{\tau_{0}}\right)^{3} \mathrm{e}^{-\tau_{\mathrm{m}} / \tau_{0}} \frac{\mathrm{d} \tau_{0}}{\tau_{\mathrm{m}}},
$$


where

$$
\tau_{\mathrm{m}}=\frac{2 \alpha \mu b}{l_{\mathrm{m}}} .
$$

This distribution is drawn in figure 10 as a function of $\tau_{\mathrm{m}}$. A maximum appears for $\tau_{0}=\tau_{\mathrm{m}} / 2$, corresponding to the liberation of a great density of dislocations at this stress level.

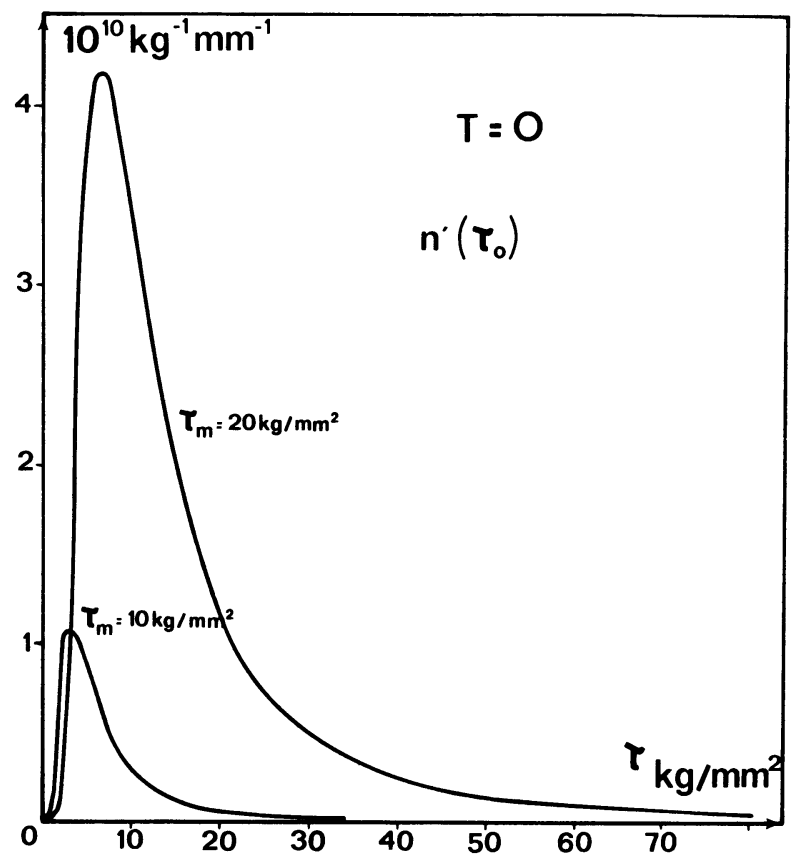

FIG. 10. - Distribution of the initial number of dislocation fragments per unit volume as a function of their critical stress of mobility at $T=0$.

3.3 Fragmentation MEChanism. - At absolute zero, when the stress is applied, edge dislocations of large $l$ first move and interact with impurities as described in figure 11.

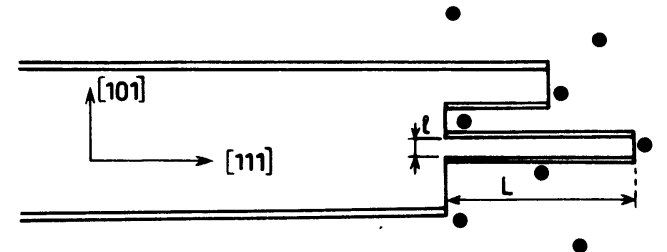

FIG. 11. $-=$ screw dislocation. - edge dislocation.

If the total length of edge dislocations line remains constant, the number of fragments increase and their average length decreases during the preplastic strain. The initial distribution $n(l)$ is then continuously modified (Fig. 12).

A number $N(l) \mathrm{d} l$ of dislocations with length between $l=\frac{\alpha \mu b}{\tau_{0}}$ and $l+\mathrm{d} l$, is freed when the stress increase from $\tau_{0}$ to $\tau_{0}+\mathrm{d} \tau_{0}$, and can be called $N^{\prime}\left(\tau_{0}\right) \mathrm{d} \tau_{0}$. At stress $\tau_{0}$ dislocations of length $l^{\prime}>l$ have been already liberated, then fragmented; they have become segments of length $l^{\prime \prime}<l$ so that no

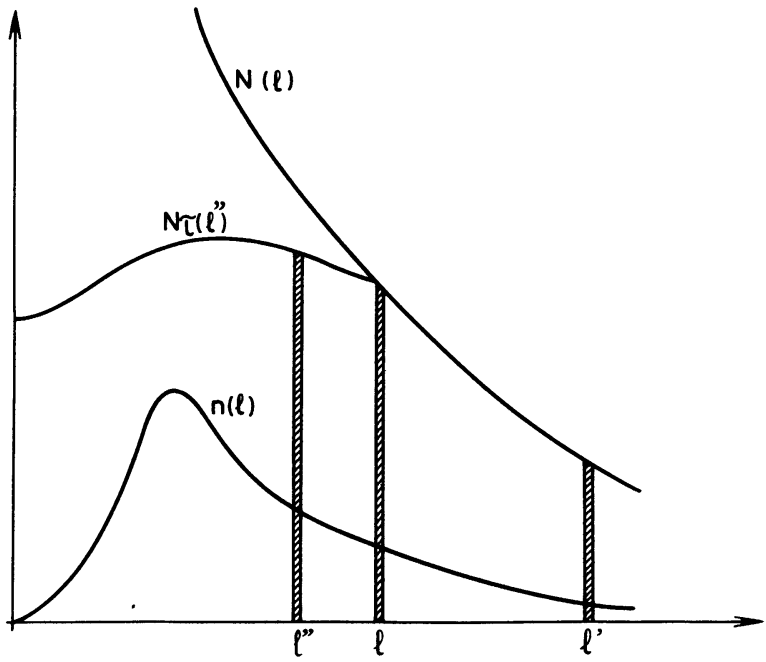

Fig. 12. - Calculation of the distribution functions of edge dislocation lengths, $l$.

dislocations longer than $l$ exists any more in the crystal at this stress, while new segments $l^{\prime \prime}<l$ must be added to the initial distribution $n(l)$. The new distribution of dislocation segments at $\tau_{0}, N_{\tau}\left(l^{\prime \prime}\right)$ is shown in figure 12.

It is assumed that dislocations of length $l^{\prime}$ give by fragmentation an homogeneous distribution of smaller fragments, the length of which are between 0 and $l^{\prime}$. If $N(l)$ is the number of fragments liberated at $\tau_{0}^{\prime}=\frac{\alpha \mu b}{l^{\prime}}$, the total length of the fragments which will fall inside the interval $l, l+\mathrm{d} l\left(l<l^{\prime}\right)$ is :

$$
\frac{\mathrm{d} l}{l^{\prime}}\left[l^{\prime} N\left(l^{\prime}\right) \mathrm{d} l^{\prime}\right]=\mathrm{d} l \mathrm{~d} l^{\prime} N\left(l^{\prime}\right) .
$$

The total length of fragments accumulated in the interval $l, l+\mathrm{d} l$ at the stress $\tau_{0}=\frac{\alpha \mu b}{l}$ is :

$$
l N(l) \mathrm{d} l=\ln (l) \mathrm{d} l+\int_{l}^{\infty} \mathrm{d} l \mathrm{~d} l^{\prime} N\left(l^{\prime}\right)
$$

or

$$
l N(l)=\ln (l)+\int_{l}^{\infty} N\left(l^{\prime}\right) \mathrm{d} l^{\prime}
$$

$n(l)$ being given by eq. (4).

The solution of this functional equation is (appendix II) :

$$
N(l) \mathrm{d} l=l_{\mathrm{m}}^{-3}\left[\left(\frac{l_{\mathrm{m}}}{l}\right)^{2}+2\right]\left[1+\frac{2 l}{l_{\mathrm{m}}}\right] \mathrm{e}^{-2 l l_{\mathrm{m}}} \frac{\mathrm{d} l}{l_{\mathrm{m}}} .
$$

Using eq. (1), the number of fragments liberated by an increase $\mathrm{d} \tau_{0}$ of the stress $\tau_{0}$ is given by $N^{\prime}\left(\tau_{0}\right) \mathrm{d} \tau_{0}$ where

therefore

$$
N^{\prime}\left(\tau_{0}\right) \mathrm{d} \tau_{0}=-N(l) \mathrm{d} l
$$

$N^{\prime}\left(\tau_{0}\right)=\frac{\tau_{\mathrm{m}}^{2}}{(2 \alpha \mu b)^{3}}\left(2+2 \frac{\tau_{\mathrm{m}}}{\tau_{0}}+\frac{\tau_{\mathrm{m}}^{2}}{\tau_{0}^{2}}+\frac{\tau_{\mathrm{m}}^{3}}{\tau_{0}^{3}}\right) \mathrm{e}^{-\tau_{\mathrm{m}} / \tau_{0}}$. 
This function is shown in figure 13 for various values of $\tau_{\mathrm{m}}$ (i.e. of the prestrain). A maximum is observed for $\tau=\tau_{\mathrm{m}} / 2$ and a constant value $\frac{1}{4} \frac{\tau_{\mathrm{m}}^{2}}{(\alpha \mu b)^{3}}$ is reached at high stresses.

This constant value is, in fact, much more a result of the fragmentation mechanism than the shape of the initial distribution. It is possible to check that it remains unchanged if the following forms for $n(l)$ are used : $A \mathrm{e}^{-B l}, A l \mathrm{e}^{-B l}, A l^{2} \mathrm{e}^{-B l} \ldots$ (13).

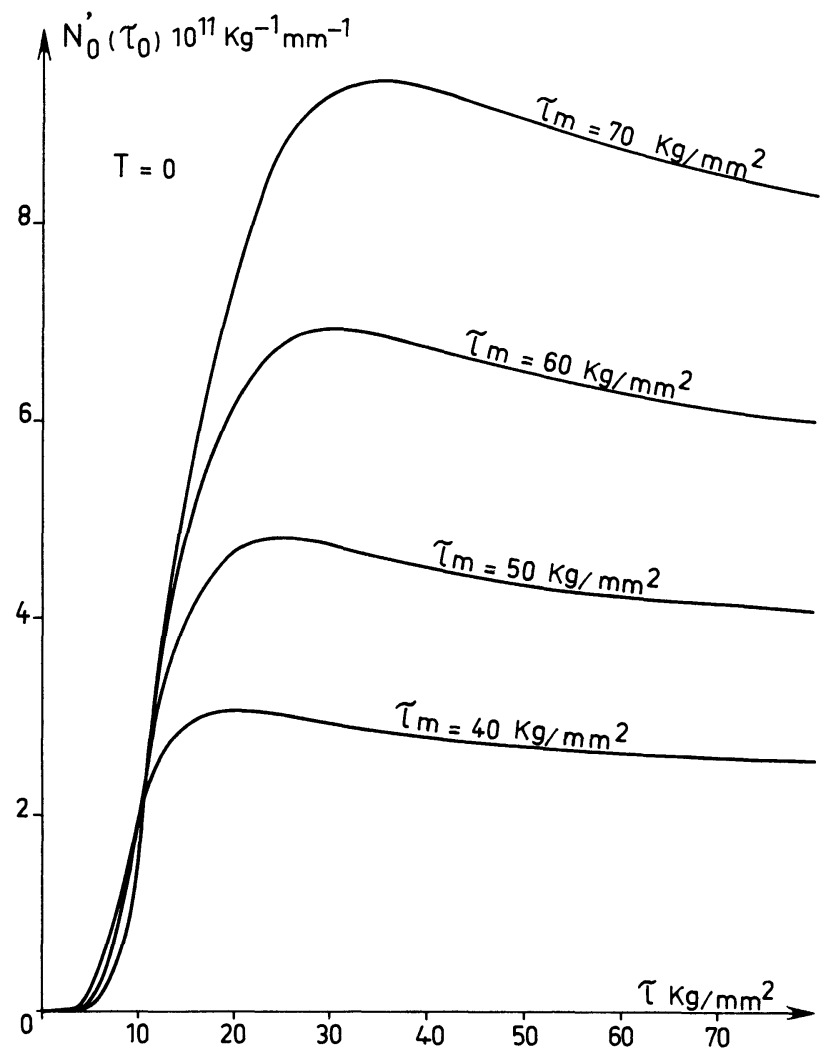

FIG. 13. - Number of mobile edge dislocations per unit volume versus the stress $\tau$.

3.4 PReyield Deformation at NON ZeRo TEMPERATURES. - At a temperature $T$, the critical stress for crossing over the interstitial impurities is reduced by thermal activation. It becomes :

$$
\tau_{T}=\tau_{0}-\Delta \tau(T) .
$$

The number $N_{T}(\tau)$ of dislocations which are mobile at the stress $\tau$ and at the temperature $T$ is given by :

$$
N_{T}(\tau) \mathrm{d} \tau=N^{\prime}\left(\tau_{0}\right) \mathrm{d} \tau_{0} \quad \text { with } \tau_{0}=\tau+\Delta \tau(T)
$$

$\Delta \tau(T)$ is given by the parameters of thermal activation. Since no detailed measurements are available on the dislocation impurity mechanism, a possible value of the activation volume is assumed, in order to illustrate the influence of temperature. As the dislocation approaches the obstacle under stress before passing it by a thermally activated jump, it is feasible to choose :

$$
V=\frac{K}{\tau} \quad \text { or } \quad V=\beta \frac{\mu b^{3}}{\tau}
$$

where $V$ is the activation volume. The activation volume is then proportional to the length $l$ of the fragment. Moreover it is not very far from the variation law calculated in the Fleischer model $[18,19]$.

According to the theory of the thermally activated phenomena, $\tau_{T}$ and $\Delta \tau(T)$ can be evaluated from eq. (6) : with $V=-\left(\frac{\partial \Delta G}{\partial \tau}\right)_{T}$ the integration gives

$$
\Delta G=\beta \mu b^{3} \log \frac{\tau_{0}}{\tau} .
$$

According to the Arrhénius law

$$
\Delta G=k T \log \frac{\dot{\gamma}_{0}}{\dot{\gamma}}=C k T
$$

with $C \simeq 25$ for current values of $\dot{\gamma}$ and $\dot{\gamma}_{0}$ one obtains :

and

$$
\tau=\tau_{0} \exp \left(-\frac{C k T}{\beta \mu b^{3}}\right)
$$

$$
N_{T}(\tau)=\exp \left(\frac{C k T}{\beta \mu b^{3}}\right) N_{0}^{\prime}\left(\tau \exp \frac{C k T}{\beta \mu b^{3}}\right) .
$$

If necessary, the value of $\beta$ in eq. (7) can be determined from temperature changes such as shown in figure 6. If the same dislocations are mobile at stresses $\tau_{1}$ and $\tau_{2}$ at the temperatures $T_{1}$ and $T_{2}$,

$$
\beta=\frac{C k\left(T_{1}-T_{2}\right)}{\mu b^{3} \log \frac{\tau_{2}}{\tau_{1}}} .
$$

From figure $6, \beta=0.073$ and

$$
V=\frac{2.8 \times 10^{2}}{\tau} b^{3} \quad\left(\tau \mathrm{in} \mathrm{kg} / \mathrm{mm}^{2}\right) .
$$

This corresponds to typical values of $V$ between $10-50 b^{3}[9]$.

The curves $N_{T}(\tau)$ can be calculated using this value, and are given in figure 14. The asymptotic value is

$$
\frac{1}{4} \frac{\tau_{\mathrm{m}}^{2}}{(\alpha \mu b)^{3}} \exp \frac{C k T}{\beta \mu b^{3}} .
$$

3.5 MEAN FREE PATH. - In a plane containing the $\langle 111\rangle$ slip direction and the $\langle 110\rangle$ edge direction, one atom occupies a surface $a^{2}$ where $a$ is the cell parameter. If $c$ is the concentration of interstitial atoms, on average one impurity atom is found over a surface $a^{2} / c$. This area is the area covered by a dislocation after a thermally activated event, i.e. $l L$, if $L$ is the mean free path (Fig. 11). 


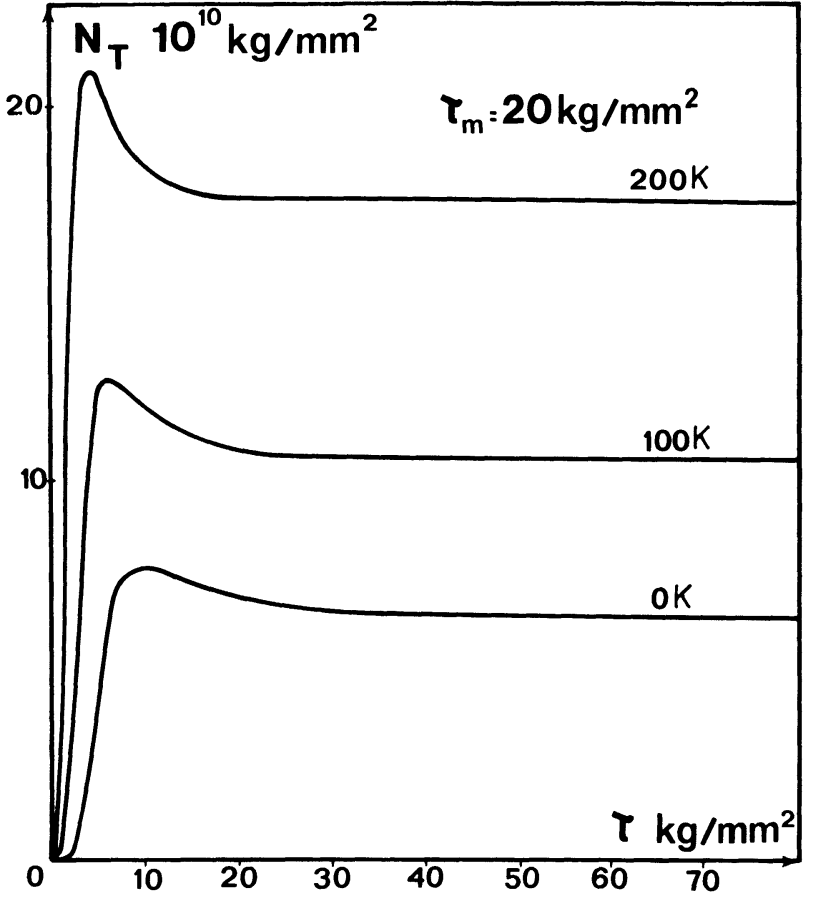

Fig. 14. - Same as figure 13, for different temperatures and a fixed value of $\tau_{\mathrm{m}}$.

Then :

$$
L=\frac{a^{2}}{c l}=\frac{a^{2} \tau}{\alpha \mu b} \frac{1}{c}
$$

(for $\alpha=1, \quad c=100 \mathrm{ppm}$, and $\tau / \mu=5 \times 10^{-3}$, $L=67 \AA$ ). When the applied stress is increased, there are shorter dislocations covering longer paths, but the area covered remains a constant.

For the sake of simplicity, it is assumed here that there is an homogeneous repartition of the interstitial impurities, and that they do not cluster, nor interact on neighbouring glide planes.

3.6 STRESS-STRAIN CURVES. - The strain is found by integrating equation (3) :

$$
\begin{aligned}
\mathrm{d} \gamma & =b L I N(l) \mathrm{d} l=-b L l N^{\prime}\left(\tau_{0}\right) \mathrm{d} \tau_{0}=-b L I N_{T}(\tau) \mathrm{d} \tau \\
\mathrm{d} \gamma & =-\frac{a^{2} b}{c} N_{T}(\tau) \mathrm{d} \tau=-\frac{a^{2} b}{c} N^{\prime}\left(\tau_{0}\right) \mathrm{d} \tau_{0} \\
\gamma(\tau) & =\frac{a^{2} b}{c} \int_{0}^{\tau_{0}} N^{\prime}\left(\tau_{0}\right) \mathrm{d} \tau_{0}
\end{aligned}
$$

where $\tau_{0}$ is given by eq. (7).

The values of the strain are integrated in appendix III, and graphically represented in figure 15 . The slope

$$
\frac{\mathrm{d} \tau}{\mathrm{d} \gamma} \propto \frac{1}{N_{T}}
$$

decreases rapidly at $\tau=\tau_{\mathrm{m}} / 4$ (at $T=0 \mathrm{~K}$ ). This corresponds to the liberation of a great density of edge dislocations. At higher stress, this density remains almost a constant.

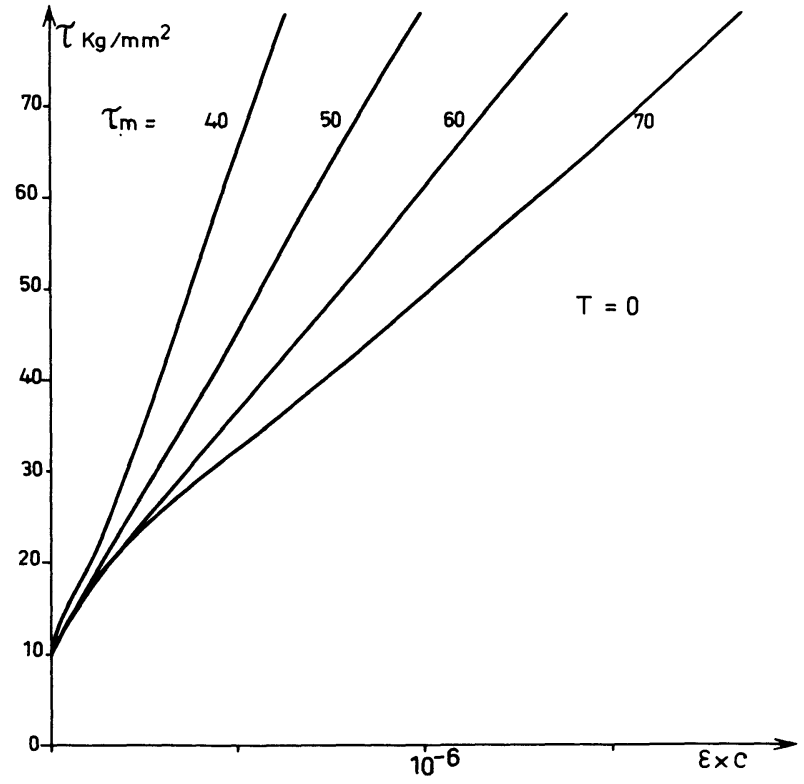

FIG. 15. - Theoretical stress-strain curves for different values of $\tau_{\mathrm{m}}$ Scale of $\gamma$ in $1 / c$ units. At a temperature $T$, the scale of $\tau$ must be divided by $: \exp \left(C k T / \beta \mu b^{3}\right)$. Theses curves must be limited at higher values of $\tau$ by the macroelastic limit.

3.7 StResS RELAXATION EXPERIMENTS. - It has been shown elsewhere [15] that stress relaxation in the preyield domain is also governed by some kind of exhaustion mechanism. These effects are illustrated in figure 8. The shape of the stress-strain curve is changed by the previous relaxation; and no supply of mobile dislocations is available till a critical stress level is reached. In other words, owing to the small density in mobile dislocations at the beginning of a stress relaxation experiment, dislocations which should be mobile at higher stresses have already been liberated.

Consequently, one does not measure the true activation volume, $V$, but an apparent value, $V^{*}$ given by [15].

$$
V^{*}=V\left[1+\frac{1}{M}\left(\frac{\mathrm{d} \tau}{\mathrm{d} \gamma}\right)\right] .
$$

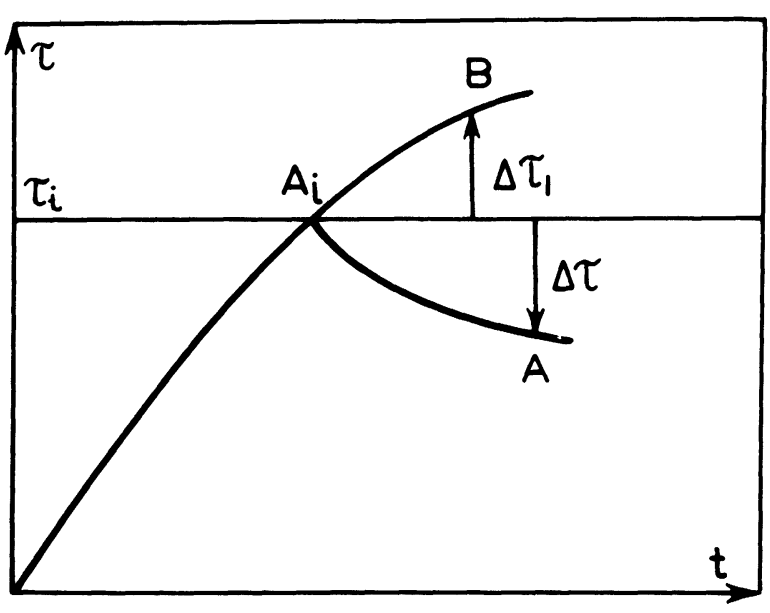

Fig. 16. - Exhaustion stress-relaxation experiment. 
$V^{*}$ can be measured from figure 16.

$$
\frac{\Delta \tau_{1}}{\Delta \tau}=1-\frac{V^{*}}{V}
$$

From the values of $\Delta \tau_{1}$ and $\Delta \tau$, one can deduce $\frac{\mathrm{d} \tau}{\mathrm{d} \gamma}$; then, from eq. (8), $N_{T}$ and check the calculated values of $N_{T}$. Inversely, from the variation of $N_{T}$, one can infer that some singularities should appear in the apparent activation volume at stresses $\tau \sim \tau_{\mathrm{m}} / 4$. It seems that these singularities have been observed in niobium in the temperature range 20-60 K [23]. It has also been observed that if the sample is loaded a second time after a first preyield stress-strain curve, the singularities do not appear, which is consistent with an exhaustion mechanism.

4. Comparison with the experimental results and discussion. - The modifications in the stress-strain curve consecutive to variations in temperature, prestrain rate or impurity concentrations correspond to what is experimentally recorded. From comparison between figure 4 on one hand and figure 15 on the other hand, it appears that the general shapes of the curves are similar. The two substages also exist in the calculated curves.

Since the proposed model is very rough, we only have to check the orders of magnitude between the experimental and calculated results.

4.1 INFluence OF THE PRESTRAIN. - The best fit for the stress-strain curves is obtained for an impurity concentration $c=30 \mathrm{ppm}$. Using the resolved stress and strain $\tau=\sigma / 2$ and $\gamma=\sqrt{2} \varepsilon, \tau_{\mathrm{m}}$ is measured from the asymptotic value of the slope $\mathrm{d} \sigma / \mathrm{d} \varepsilon$.

$$
\left(\frac{\mathrm{d} \sigma}{\mathrm{d} \varepsilon}\right)_{\infty}=6 \sqrt{2} c \frac{(\alpha \mu)^{3}}{\tau_{\mathrm{m}}^{2}} \exp -\frac{C k T}{\beta \mu b^{3}} .
$$

$\beta$ is known from paragraphe 3.4 and $\alpha$ is taken to be the unity. The total dislocation density resulting from the prestrain is given by :

$$
\mathcal{L}=\left(\frac{\tau_{\mathrm{m}}}{2 \alpha \mu b}\right)^{1 / 2}
$$

The results for the stress-strain curves at $4.2 \mathrm{~K}$ are

\begin{tabular}{|c|c|c|c|c|c|}
\hline$\gamma_{p}$ & 0,5 & 1 & 2 & 4 & $3(77 \mathrm{~K})$ \\
\hline 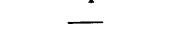 & $\longrightarrow$ & - & - & - & - \\
\hline$\tau_{\mathrm{m}} \mathrm{kg} / \mathrm{mm}^{2}$ & 37 & 54 & 64 & 70 & 45 \\
\hline $\mathcal{L} 10^{9} \mathrm{~cm}^{-2}$ & 19 & 53 & 77 & 90 & 37 \\
\hline
\end{tabular}
given in the table I below :

\section{TABLE I}

These values of $\tau_{\mathrm{m}}$ agree with the values of $\tau_{\mathrm{m}} / 4$ measured at the transition between the two substages. The values of $\mathcal{L}$ are given in figure 17 as a function of

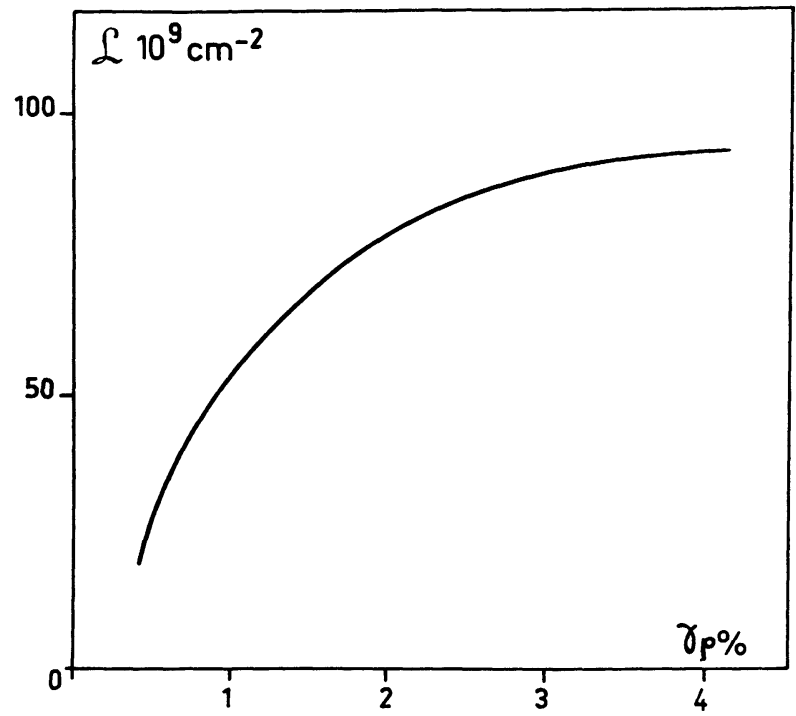

FIG. 17. - Total edge dislocation length generated by a prestrain $\gamma_{\mathbf{p}}$.

the prestrain $\gamma_{\mathrm{p}}$. Of course these values depend on the impurity concentration which is not accurately known because of the uncertainties described in paragraphe 3.5.

From the table I and figure 15, one can evaluate the strains corresponding to given prestrain, temperature and stress and calculate the low temperature strain during the first cycle as a function of the prestrain mesured on figure 3. The corresponding theoretical curve is given in figure 18 and appears to be in good agreement with the experimental values.

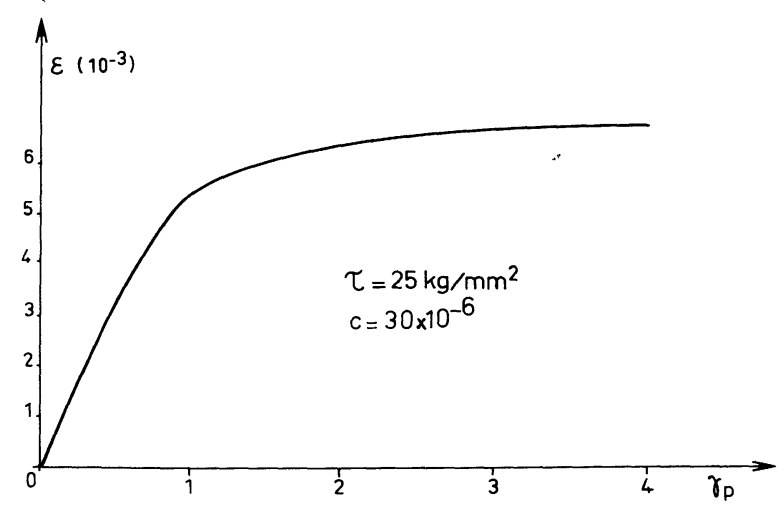

FIG. 18. - Theoretical tensile strain at a fixed stress versus the prestrain $T=0$.

From figure 17, it appears that the saturation experimentally observed in the preyield strain versus prestrain curve (Fig. 3) is a consequence of the prestrain itself : the large room temperature prestrains do not greatly increase the edge dislocation densities.

Clearly, the influence of prestrain is related to only one parameter, the initial dislocation density $\mathcal{L}$. This is why the detailed shape of the statistical law $n(l)$ has no influence on the results.

The decrease of the work hardening rate of the second substage at larger prestrain is due to the 
greater value of $N_{0}^{\prime}\left(\tau_{0}\right)$ and can be related to the experimental observation of catastrophic slip, at low temperatures [24] in high prestrained samples : in these cases the rate of liberation of the dislocations is large enough to induce a positive feedback process between the thermally activated glide and the heat liberated by it.

Preyield stress-strain curves exhibiting two substages have also been observed in other materials than niobium (e.g. tantalum) [25].

According to this model, the two substages should correspond to only one deformation mechanism but to different mobile dislocation densities.

4.2 INFLUENCE OF TEMPERATURE. - At a temperature $T$, the transition between the two substages occurs at a stress :

$$
\tau_{T}=\frac{\tau_{\mathrm{m}}}{4} \exp \left(-\frac{C k T}{\beta \mu b^{3}}\right) .
$$

Simultaneously, the yield stress decreases, but more rapidly. At some critical temperature $T_{\mathrm{c}}$, the two stresses meet, i.e. the whole preyield domain can be described by the first substage only.

For $\tau_{\mathrm{m}}=60 \mathrm{~kg} / \mathrm{mm}^{2}$. and using the temperature variation of the macroyield stress given in [23], $T_{\mathrm{c}}=220 \mathrm{~K}$.

At temperatures higher than $T_{\mathrm{c}}$ (and assuming that the preyield mechanisms described above are operative) it should only be possible to find the substage with a high hardening rate.

4.3 STRESS RELAXATION EXPERIMENTS. - The variation of the apparent activation volume with the amount of prestrain can be understood through the value of $\frac{\mathrm{d} \tau}{\mathrm{d} \gamma} \propto \frac{1}{N_{T}}$ in eq. (9). In fact, parallel conclusions can be drawn from relaxation and cycling experiments though the former are technically more difficult to perform.

4.4 Conclusion. - We draw the following conclusions from our experiments on the preyield behaviour of niobium :

1) The whole preyield domain is governed by a thermally activated phenomenon. The behaviour of each discrete dislocation density mobile at a given stress is probably dependent on a dislocation-impurity interaction.

2) A spectrum exists for this interaction, arising from the different lengths of the mobile dislocations which are of the edge type.

3) Exhaustion mechanisms are strongly dependent on the supply of edge dislocations provided by a room temperature prestrain. This is revealed either by stress relaxation or by cycling experiments.

4) This behaviour is described as a dislocation fragmentation associated to a thermally activated event.
Despite the numerous experimental uncertainties, this model is able to explain all the experimental results reasonably well within orders of magnitude for the parameters which can be calculated.

5) Because the hypotheses are simple, we may hope that this model applies to the preyield domain of other BCC materials.

Appendix I. - DENSITY OF MOBILE DISLOCATION DUE TO PRESTRAIN. - The law $n(l)=A l \mathrm{e}^{-B l}$ finds its justification in statistical arguments. Suppose we have first a single straight dislocation of length $\mathcal{L}$ in unit volume of crystal. During deformation it glides in a plane where $n$ obstacles are distributed at random. The probability for the obstacle to be crossed by a segment $\mathrm{d} l$ is $\mathrm{d} l / \mathcal{L}$. Divide the dislocation into smaller segments of length $l$. The probability that a given segment crosses any of the obstacles is

$$
p=n \frac{l}{\mathfrak{L}}\left(1-\frac{l}{\mathfrak{L}}\right)^{n-1}
$$

If we put

$$
l_{0}=\frac{\mathfrak{L}}{n}, p \simeq \frac{l}{l_{0}}\left(1-\frac{l}{\mathcal{L}}\right)^{\mathfrak{L} / l_{0}}
$$

and $n(l)$ is proportional to $p$.

When $\mathcal{L}$ is great, $n(l) \rightarrow A \frac{l}{l_{0}} \mathrm{e}^{-l / l_{0}}$.

The constants $A$ and $B$ can be determined as follows.

The total length is :

$$
\mathcal{L}=\int_{0}^{\infty} \ln (l) \mathrm{d} l=\frac{2 A}{B^{3}} .
$$

The mean length is :

$$
l_{\mathrm{m}}=\frac{2}{B} \text {. So } B=\frac{2}{l_{\mathrm{m}}} \text { and } A=\frac{B^{3} \mathcal{L}}{2}=\frac{4 \mathcal{L}}{l_{\mathrm{m}}^{3}} \text {. }
$$

Now remark that $l_{\mathrm{m}}$ and $\mathcal{L}$ are linked by the geometrical arrangement. $l_{\mathrm{m}}$ measures the side of the Frank net and $l_{\mathrm{m}} \simeq \mathfrak{L}^{-1 / 2}$.

So

$$
\begin{gathered}
A=4 l_{\mathrm{m}}^{-5} \\
n(l) \mathrm{d} l=4 l_{\mathrm{m}}^{-5} \exp \left(-\frac{2 l}{l_{\mathrm{m}}}\right) \mathrm{d} l
\end{gathered}
$$

$l_{\mathrm{m}}$ is then the only parameter representing the influence of the prestrain.

Appendix II. - Calculation of THE Distribution $N(l)$. - The equation to be resolved is :

$$
l N=\ln +\int_{l}^{\infty} N \mathrm{~d} l
$$


Figure 12 shows the signification of the different symbols. One has :

$$
\begin{gathered}
n=A l \mathrm{e}^{-B l} \\
\mathcal{L}=\int_{0}^{\infty} \ln \mathrm{d} l=\int_{0}^{l} l^{\prime \prime} N_{Z}\left(l^{\prime \prime}\right) \mathrm{d} l^{\prime \prime} \\
l^{\prime \prime} N_{Z}\left(l^{\prime \prime}\right)=l^{\prime \prime} n\left(l^{\prime \prime}\right)+\int_{l}^{\infty} N \mathrm{~d} l \text { for } l^{\prime \prime}<l .
\end{gathered}
$$

From (1) one finds :

$$
2 N+l N^{\prime}=n+l n^{\prime}
$$

From the equation without a second member :

$$
2 N+l N^{\prime}=0 \text { or } N=\mathrm{cl}^{-2} \text {. }
$$

The results and eq. (2) reported in eq. (5) give

So

$$
c^{\prime}=A \mathrm{e}^{-B l}\left(2 l^{2}-B l^{3}\right) \text {. }
$$

$$
c=A \mathrm{e}^{-B l}\left(\frac{2}{B^{3}}+\frac{2}{B^{2}} l+\frac{1}{B} l^{2}+l^{3}\right)+K
$$

and

$$
N=\frac{K}{l^{2}}+A \mathrm{e}^{-B l}\left(\frac{2}{B^{3}} l^{-2}+\frac{2}{B^{2}} l^{-1}+\frac{1}{B}+l\right) .
$$

From (4)

$$
\begin{array}{r}
\mathcal{L}=\int_{0}^{l} l^{\prime \prime} N_{\tau}\left(l^{\prime \prime}\right) \mathrm{d} l^{\prime \prime}=\int_{0}^{l} \ln \mathrm{d} l+\int_{0}^{l} \mathrm{~d} l^{\prime \prime} \int_{l}^{\infty} N \mathrm{~d} l= \\
=\int_{0}^{l} \ln \mathrm{d} l+l \int_{l}^{\infty} N \mathrm{~d} l .
\end{array}
$$

When $l \rightarrow \infty$,

$$
\int_{0}^{l} \ln \mathrm{d} l \rightarrow \mathcal{L} \text { then } l \int_{l}^{\infty} N \mathrm{~d} l \rightarrow 0 .
$$

Taking for $N$ the expression (6), one can show [13] that

$$
l \int_{l}^{\infty} N \mathrm{~d} l \rightarrow K
$$

when $l \rightarrow \infty$. So $K=0$.

With $A=4 l_{\mathrm{m}}^{-5}$ and $B=2 l_{\mathrm{m}}^{-1}$, one obtains :

$$
N=l_{\mathrm{m}}^{-4}\left[\left(\frac{l_{\mathrm{m}}}{l}\right)^{2}+2 \frac{l_{\mathrm{m}}}{l}+2+4 \frac{l}{l_{\mathrm{m}}}\right] \mathrm{e}^{-2 l / l_{\mathrm{m}}} \text {. }
$$

Appendix III. - Calculation of THE Strain. -

$$
\gamma=\frac{a^{2} b}{c} \int_{0}^{\tau_{0}} N_{0}^{\prime}\left(\tau_{0}\right) \mathrm{d} \tau_{0}
$$

With $x=\frac{\tau_{0}}{\tau_{\mathrm{m}}}$, one finds from eq. (1) :

$$
\begin{gathered}
\int_{0}^{\tau_{0}} N^{\prime}\left(\tau_{0}\right) \mathrm{d} \tau_{0}=\int_{0}^{l} N(l) \mathrm{d} l=l N(l)-\ln (l) \\
N(l)=-N^{\prime}\left(\tau_{0}\right) \frac{\mathrm{d} \tau_{0}}{\mathrm{~d} l}= \\
=\frac{1}{8}\left(\frac{\tau_{\mathrm{m}}}{\alpha \mu b}\right)^{4}\left(2 x^{2}+2 x+1+\frac{1}{x}\right) \mathrm{e}^{-1 / x} \\
n(l)=\frac{1}{8}\left(\frac{\tau_{\mathrm{m}}}{\alpha \mu b}\right)^{4} \frac{1}{x} \mathrm{e}^{-1 / x} \\
b=a \frac{\sqrt{3}}{2}
\end{gathered}
$$

and finally :

with

$$
\gamma(\tau)=\frac{1}{6 c}\left(\frac{\tau_{\mathrm{m}}}{\alpha \mu}\right)^{3}\left(2 x+2+\frac{1}{x}\right) \exp \left(-\frac{1}{x}\right)
$$

$$
x=\frac{\tau}{\tau_{\mathrm{m}}} \exp \frac{C k T}{\beta \mu b^{3}} .
$$

\section{References}

[1] Solomon, H. D. and Mc Mahon, C. J., Jr., Work Hardening, Metallurgical Society Conference (Ed. Gordon and Breach), 1966, p. 309.

[2] Guiv, F. and Pratt, P. L., Phys. Stat. Sol. 6 (1964) 111.

[3] Brown, N. and Ekvall, R. A., Acta Metall. 10 (1962) 1101

[4] Escaig, B., Phys. Stat. Sol. 28 (1968) 463.

[5] Saka, H., Noda, K. and Imura, T., Cryst. Lattice Defects 4 (1973) 45.

[6] Luft, A. and Kaun, L., Phys. Stat. Sol. 37 (1970) 781.

[7] Kubin, L. P. and Joufrrey, B., Phil. Mag. 27 (1973) 1369.

[8] VeselÝ, D., Phys. Stat. Sol. 29 (1968) 675.

[9] Groh, P. and ConTe, R., Acta Metall. 19 (1971) 895.

[10] Solomon, H. D. and McMahon, C. J., Jr., Acta Metall. 19 (1971) 291.

[11] Wilson, F. G. and Teghtsoonian, E., Phil. Mag. 22 (1970) 815.

[12] Feltham, P. and Hawkins, A., Mater. Sc. Eng. 17 (1975) 239.

[13] Boudet, A., Thesis, Toulouse, 1974.
[14] Boudet, A. and Kubin, L. P., C. R. Hebd. Séan. Acad. Sci. 276B (1973) 925.

[15] Kubin, L. P., Phil. Mag. 30 (1974) 705.

[16] Taylor, G., Veselý, D. and Christian, J. W., 3rd Int. Conf. on the strength of metals and alloys, Cambridge, 1973, p. 1 Institute of Metals.

[17] Korenko, M. K., Mitchell, T. E. and Gibala, R., Acta Metall. 22 (1974) 649.

[18] Fleischer, R. L., Acta Metall. 10 (1962) 835.

[19] Fleischer, R. L., J. Appl. Phys. 33 (1962) 3504.

[20] Kocks, U. F., Phil. Mag. 13 (1966) 541.

[21] LI, J. C. M., Physics of Strength and Plasticity (M.I.T. Press) 1969.

[22] Mecking, H. and Lücke, K., Scr. Metall. 4 (1970) 427.

[23] Kubin, L. P., Thesis, 1971, Université Paris-Sud.

[24] Kubin, L. P. and Joufreey, B., Phil. Mag. 24 (1971) 188.

[25] Parikh, P. D. and HaY, D. R., Scr. Metall. 5 (1971) 1039. 